\section{(6) OPEN ACCESS}

\title{
Early neurological deterioration after subarachnoid haemorrhage: risk factors and impact on outcome
}

\author{
Raimund Helbok, ${ }^{1,2}$ Pedro Kurtz, ${ }^{1}$ Matthew Vibbert, ${ }^{1}$ Michael J Schmidt, ${ }^{1}$ \\ Luis Fernandez, ${ }^{1}$ Hector Lantigua, ${ }^{1}$ Noeleen D Ostapkovich, ${ }^{1}$ Sander E Connolly, ${ }^{1,3}$ \\ Kiwon Lee, ${ }^{1}$ Jan Claassen, ${ }^{1}$ Stephan A Mayer, ${ }^{1,3}$ Neeraj Badjatia ${ }^{1,3}$
}

${ }^{1}$ Department of Neurology, Division of Neurocritical Care, Columbia University College of Physicians and Surgeons, New York, New York, USA ${ }^{2}$ Clinical Department of Neurology, Neurological Intensive Care Unit, Medical University Innsbruck, Innsbruck, Austria

${ }^{3}$ Department of Neurosurgery, Columbia University College of Physicians and Surgeons, New York, New York, USA

Correspondence to Professor N Badjatia, Division of Critical Care Neurology, Department of Neurology, Columbia University, Milstein Hospital 8 Center, 177 Fort Washington Ave, New York, NY 10032 USA;

NBadjatia@neuro.columbia.edu Raimund.Helbok@uki.at

Received 19 March 2012 Revised 4 July 2012 Accepted 21 August 2012 Published Online First 25 September 2012

\section{ABSTRACT \\ Background Early neurological deterioration occurs frequently after subarachnoid haemorrhage (SAH). The impact on hospital course and outcome remains poorly defined.}

Methods We identified risk factors for worsening on the Hunt-Hess grading scale within the first $24 \mathrm{~h}$ after admission in 609 consecutively admitted aneurysmal SAH patients. Admission risk factors and the impact of early worsening on outcome was evaluated using multivariable analysis adjusting for age, gender, admission clinical grade, admission year and procedure type. Outcome was evaluated at 12 months using the modified Rankin Scale (mRS).

Results 211 patients worsened within the first $24 \mathrm{~h}$ of admission (35\%). In a multivariate adjusted model, early worsening was associated with older age (OR 1.02, 95\% $\mathrm{Cl} 1.001$ to $1.03 ; p=0.04)$, the presence of intracerebral haematoma on initial CT scan (OR 2.0, 95\% Cl 1.2 to 3.5; $p=0.01$ ) and higher SAH and intraventricular haemorrhage sum scores (OR 1.05, 95\% Cl 1.03 to 1.08 and $1.1,95 \% \mathrm{Cl} 1.01$ to $1.2 ; \mathrm{p}<0.001$ and 0.03 , respectively). Early worsening was associated with more hospital complications and prolonged length of hospital stay and was an independent predictor of death (OR $12.1,95 \% \mathrm{Cl} 5.7$ to $26.1 ; \mathrm{p}<0.001)$ and death or moderate to severe disability (mRS 4-6, OR $8.4,95 \% \mathrm{Cl}$ 4.9 to $14.5 ; p=0.01$ ) at 1 year.

Conclusions Early worsening after SAH occurs in 35\% of patients, is predicted by clot burden and is associated with mortality and poor functional outcome at 1 year.

\section{BACKGROUND}

Subarachnoid haemorrhage (SAH) is associated with a high mortality and morbidity. ${ }^{1}$ The detrimental effect of medical complications in the first 2 weeks after haemorrhage on long term outcome has been extensively studied. ${ }^{2-5}$ Additional determinants of poor outcome after SAH include age, neurological state at presentation and large aneurysm size. ${ }^{1}$ After the initial neuronal damage caused by the haemorrhage, neurological decline is often observed. Clinical worsening may occur early (within the first $24 \mathrm{~h}$ of admission) or late in the course of the disease. Several factors have been associated with clinical deterioration, including aneurysm rebleeding, hydrocephalus, delayed cerebral ischaemia from vasospasm, and seizures. ${ }^{4}$ 6-10 However, admission variables predicting early neurological decline have not been evaluated, and the impact of early worsening on hospital course and outcome received little attention as a prognostic variable after $\mathrm{SAH}$. In this study we sought to identify predictors for early worsening after $\mathrm{SAH}$ and to determine the impact of worsening on outcome.

\section{METHODS}

Patient population and clinical management All SAH patients admitted to the Neurological Intensive Care Unit of Columbia University Medical Center between July 1996 and May 2009 were offered enrolment in the Columbia University $\mathrm{SAH}$ Outcomes Project $(n=1227)$. Consent rate was $98 \%$. Thestudywasapproved bythehospital'sinstitutional review board, and in all cases written informed consent was obtained from the patient or a surrogate. The diagnosis of SAH was established by admission CTscan or by xan thochromia of the CSF if CTwas not diagnostic. Patients with SAH due to trauma, arteriovenous malformation, vasculitis or other structural lesions $(n=242)$, aswell asthose aged $<18$ years $(n=6)$ oradmitted $>24$ hafter SAHonset $(n=237)$ and those without recorded Hunt-Hess grades on admission and worst Hunt-Hess grade within the first $24 \mathrm{~h}$ $(n=24)$ were excluded. Additionally, admission Hunt-Hess grade $V$ patients were not included in the final analysis due to inability of further deterioration $(n=109)$. Clinical management according to guidelines set forth by the American Heart Association has been described in detail previously. ${ }^{3411}$ We record the dayofaneurysmalSAHas 'day0' in ourdatabase.

\section{Clinical and radiographic variables, and hospital complications}

We recorded baseline demographic data, social and past medical history, clinical features at SAH onset and admission CT scan, as described previously. ${ }^{3} 4 \quad 12 \quad 13$ Neurological and general medical condition on admission was evaluated with the Hunt-Hess scale $e^{12}$ and the physiological subscore of the Acute Physiology and Chronic Health Evaluation (APACHE)-2 scale. ${ }^{11}$ Hunt-Hess grades on admission and at $24 \mathrm{~h}$ were evaluated by the treating neurointensivist (JC, NB, KL, SAM) and recorded. Hospital complications were prospectively recorded according to standardised definitions, including fever (body temperature $\geq 38.3^{\circ} \mathrm{C}$ ), anaemia treated with blood transfusion (haemoglobin $<9.0 \mathrm{~g} / \mathrm{l}$ ), aneurysm rebleeding, brainstem herniation, cerebral infarction (from any cause), 
hydrocephalus treated with CSF diversion, hyperglycaemia (blood glucose $>11 \mathrm{mmol} / \mathrm{l}$ ), hyponatraemia (serum sodium $\leq 130 \mathrm{mmol} / \mathrm{l}$ ), hypotension (systolic blood pressure $<100 \mathrm{~mm} \mathrm{Hg}$ ) requiring pressors, sepsis, pneumonia, pulmonary oedema, seizures and delayed cerebral ischaemia (delayed neurological deterioration, cerebral infarction or both) due to vasospasm. ${ }^{2} 1415$ The Bicaudate Index was used as an estimated measure for the development of hydrocephalus.

\section{Early neurological deterioration}

In every patient, admission Hunt-Hess grade and the worst Hunt-Hess grade within the first $24 \mathrm{~h}$ of admission were recorded. Early neurological deterioration was defined as any increase in Hunt-Hess scale within the first $24 \mathrm{~h}$ of admission, with grades I and II combined as a single group of good grade patients. Procedure or sedation related deterioration was not considered as 'early neurological deterioration'. The second evaluation was done 'sedation free' so as to minimise the effect of sedation. If sedation was considered the culprit, then a higher score was not assigned. External ventricular drain (EVD) placement was immediately performed in symptomatic patients, even before aneurysm repair. In general, EVD was in place by the time of the second score. In patients with early neurological deterioration, hydrocephalus requiring EVD placement was performed in 27\% (admission Hunt-Hess grades 1 and 2, $\mathrm{n}=24 / 90$ ), $61 \%$ (admission Hunt-Hess grade 3, $\mathrm{n}=42 / 69$ ) and $81 \%$ (Hunt-Hess grade $4, \mathrm{n}=42 / 52$ ). Predictors for early neurological deterioration included only variables obtained on admission (demographics, past medical history, neurological and clinical examination, laboratory analyses and radiographic findings).

\section{Outcome variables}

Survival and functional outcomes were assessed at discharge and at 3 and 12 months, using the modified Rankin Scale (mRS). ${ }^{16}$ Poor outcome was defined as death or moderate to severe disability (mRS 4-6) at 12 months. If a 12 month mRS was not performed, day 14 (or discharge) or 3 month evaluation was carried forward.

\section{Statistical analysis}

All statistical analyses were performed using SPSS 18 software (SPSS Inc, Chicago, Illinois, USA). Significance was judged at $p<0.05$. Candidate predictor variables for worsening and mortality were identified by $\chi^{2}$ or Fisher exact tests for categorical variables and the Mann-Whitney $\mathrm{U}$ or two tailed t tests for continuous variables (table 1). Normality was assessed using the Kolmogorov-Smirnov test. Among similar variables that were highly intercorrelated (ie, clinical scales), only the variable with the highest $\mathrm{OR}$ and smallest $\mathrm{p}$ value in the binary logistic regression analysis was used as a candidate variable in the final multivariate model. Independent predictors of early worsening, death at 12 months and death or severe disability at 12 months were identified with backward stepwise multiple logistic regression analysis. Factors that occurred at a frequency of $<5 \%$ were excluded from the final model. To determine the relative contributions of the individual predictors, we used Bayesian information criterion and Akaike's information criterion of the entire model after individual removal of each significant predictor. Tests for interaction were performed for all variables entered into the multivariable models. When significant two way interactions were identified, we reanalysed the predictive value of each factor after stratifying the analysis between the two levels of the other factor.
Table 1 Admission factors in relation to neurological deterioration in the first $24 \mathrm{~h}(\mathrm{n}=609)$

\begin{tabular}{|c|c|c|c|}
\hline & $\begin{array}{l}\text { Worse } \\
(n=211)\end{array}$ & $\begin{array}{l}\text { Stable } \\
(\mathrm{n}=398)\end{array}$ & p Value \\
\hline \multicolumn{4}{|l|}{ Demographics } \\
\hline Age (years) & $57(16)$ & $52(13)$ & 0.001 \\
\hline Female & $154(73)$ & $297(75)$ & 0.6 \\
\hline Body mass index $\left(\mathrm{kg} / \mathrm{m}^{2}\right)$ & $27(6)$ & $27(7)$ & 0.9 \\
\hline White ethnicity & $99(47)$ & $180(45)$ & 0.7 \\
\hline \multicolumn{4}{|l|}{ Social and past medical history } \\
\hline Hypertension & $118(56)$ & $175(43)$ & 0.004 \\
\hline Diabetes mellitus & $17(8)$ & $28(7)$ & 0.3 \\
\hline Previous stroke & $7(3)$ & $7(2)$ & 0.2 \\
\hline \multicolumn{4}{|c|}{ Admission neurological and clinical findings } \\
\hline Hunt-Hess grade & $3(2-3)$ & $3(1-3)$ & 0.3 \\
\hline 1 and 2, alert and oriented & $90(43)$ & $179(45)$ & \\
\hline 3 , lethargic & $69(33)$ & $137(34)$ & \\
\hline 4 , stuporous & $52(25)$ & $82(21)$ & \\
\hline Loss of consciousness & $92(44)$ & $134(34)$ & 0.01 \\
\hline APACHE-2 physiological subscore* & $6(4-9)$ & $5(3-8)$ & $<0.001$ \\
\hline Body temperature $\left({ }^{\circ} \mathrm{C}\right)$ & 98 (97-99) & 98 (97-99) & 0.8 \\
\hline Systolic blood pressure (mm Hg) & $160(138-180)$ & $156(133-180)$ & 0.2 \\
\hline Heart rate $(\mathrm{bpm})$ & $82(69-96)$ & $80(68-90)$ & 0.3 \\
\hline Respiratory rate (/min) & $18(16-20)$ & $18(16-20)$ & 0.1 \\
\hline Serum sodium (mmol/l) & $139(136-140)$ & $138(136-140)$ & 0.9 \\
\hline Serum glucose $(\mathrm{mmol} / \mathrm{l})$ & $146(126-178)$ & $137(118-166)$ & 0.003 \\
\hline White blood cell count $\left(\times 10^{9} / \mathrm{l}\right)$ & $11.6(8.8-14.5)$ & $10.8(8.3-13.7)$ & 0.08 \\
\hline Troponin $(\mu \mathrm{g} /)^{\dagger} \dagger$ & $0.2(0.02-0.5)$ & $0.1(0.02-0.3)$ & 0.4 \\
\hline \multicolumn{4}{|l|}{ Admission radiographic findings } \\
\hline Modified Fisher scale & $3(2-4)$ & $3(1-3)$ & $<0.001$ \\
\hline 0 , no blood & $1(1)$ & $12(3)$ & \\
\hline 1 , focal or diffuse thin SAH & $42(20)$ & $124(32)$ & \\
\hline $\begin{array}{l}\text { 2, focal or diffuse thin SAH } \\
\text { with bilateral IVH }\end{array}$ & $16(8)$ & $29(7)$ & \\
\hline 3 , focal or diffuse thick SAH & $95(45)$ & $162(41)$ & \\
\hline $\begin{array}{l}\text { 4, focal or diffuse thick SAH } \\
\text { with bilateral IVH }\end{array}$ & $57(27)$ & $71(18)$ & \\
\hline SAH sum score* & $19(14-24)$ & $15(10-21)$ & $<0.001$ \\
\hline IVH sum score* & $2(0-4)$ & $1(0-3)$ & 0.005 \\
\hline Bicaudate Index (mm) & $0.17(0.13-0.22)$ & $0.16(0.12-0.20)$ & 0.004 \\
\hline Haematoma & $42(20)$ & $43(11)$ & 0.003 \\
\hline $\begin{array}{l}\text { Vasospasm on admission } \\
\text { angiogram }\end{array}$ & $11(5)$ & $18(5)$ & 0.7 \\
\hline Aneurysm size $>10 \mathrm{~mm}$ & $54(26)$ & $92(23)$ & 0.4 \\
\hline
\end{tabular}

Values are presented as mean (SD), median (IQR) or number (\%).

*APACHE-2 physiological subscore is the sum of four physiological variables: arterio-alveolar gradient $>125 \mathrm{~mm} \mathrm{Hg}=3, \mathrm{HCO}_{3}<20 \mathrm{mmol} / \mathrm{l}=2$, glucose

$9.9 \mathrm{mmol} / \mathrm{l}=2$ and mean arterial pressure $<70$ or $>130 \mathrm{~mm} \mathrm{Hg}=1$ (range 0-8); SAH sum score grades the amount of blood in 10 basal cisterns and fissures $(0=$ no $S A H$, $1=$ small SAH, $2=$ moderate $\mathrm{SAH}, 3=$ completely filled with $\mathrm{SAH}$ ) by adding each of the 10 individual cistern scores (range 0-30); IVH sum score grades the amount of blood in the right and left lateral, third and fourth ventricel $(0=$ no blood,

$1=$ sedimentation, $2=$ partly filled, $3=$ completely filled) by adding each of the four individual ventricel scores (range $0-12$ ).

tMissing variables in $45 \%$.

APACHE, Acute Physiology and Chronic Health Evaluation, ICH, intracerebral haemorrhage; IVH, intraventricular haemorrhage; $\mathrm{SAH}$, subarachnoidal haemorrhage.

\section{RESULTS}

\section{Frequency of early neurological deterioration}

Of the 609 patients eligible for analysis, early worsening occurred in $35 \%$ of patients ( $n=211)$, equally distributed in patients where aneurysm was coiled (34\%) and clipped (35\%). Aneurysm repair was performed on day 1 of admission (median, IQR 1-1). Early worsening occurred by one (58\%; to 
Table 2 Multivariate analysis predicting neurological deterioration in the first $24 h^{*}$

\begin{tabular}{|c|c|c|c|}
\hline Variable & OR & $95 \% \mathrm{Cl}$ & p Value \\
\hline Age & 1.02 & 1.001 to 1.03 & 0.04 \\
\hline Intracerebral haematoma on initial CT & 2.0 & 1.2 to 3.5 & 0.01 \\
\hline SAH sum score $†$ & 1.05 & 1.03 to 1.08 & $<0.001$ \\
\hline IVH sum scoret & 1.1 & 1.01 to 1.18 & 0.03 \\
\hline
\end{tabular}

Hunt-Hess grade $3, n=63$; to Hunt-Hess grade $4, n=42$; to Hunt-Hess grade $5, \mathrm{n}=52)$, two $(34 \%$; to Hunt-Hess grade 4 , $\mathrm{n}=17$; to Hunt-Hess grade $5, \mathrm{n}=27$ ) or three $(8 \%$; to HuntHess grade $5, \mathrm{n}=10$ ) Hunt-Hess categories.

\section{Predictors of early neurological deterioration}

Of the clinical and radiographic variables associated with worsening in the univariate analysis (table 1), older age, intracerebral haematoma on initial CT scan, higher SAH sum and intraventricular haemorrhage sum scores were independent predictors of worsening within the first $24 \mathrm{~h}$ (table 2), after adjusting for admission Hunt-Hess grade, gender, admission year and procedure type (surgical/endovascular treatment of ruptured aneurysms). No interactions were found between these predictors in this final model.

\section{Hospital complications}

The rate of hospital complications was higher in patients with early neurological deterioration, as shown in table 3.

Table 3 Hospital complications and outcome in relation to neurological deterioration in the first $24 \mathrm{~h}(\mathrm{n}=609)$

\begin{tabular}{|c|c|c|c|}
\hline & $\begin{array}{l}\text { Worse } \\
(n=211)\end{array}$ & $\begin{array}{l}\text { Stable } \\
(n=398)\end{array}$ & p Value \\
\hline Fever $>38.3^{\circ} \mathrm{C}$ & $153(73)$ & $184(46)$ & $<0.001$ \\
\hline $\begin{array}{l}\text { Anaemia treated with blood } \\
\text { transfusion }\end{array}$ & $114(54)$ & $115(29)$ & $<0.001$ \\
\hline Aneurysm rebleeding & $35(17)$ & $15(4)$ & $<0.001$ \\
\hline Herniation & $52(25)$ & $18(5)$ & $<0.001$ \\
\hline $\begin{array}{l}\text { Hydrocephalus treated with CSF } \\
\text { diversion }\end{array}$ & $108(51)$ & $104(26)$ & $<0.001$ \\
\hline Hyperglycaemia (>11 mmol/l) & $124(59)$ & $171(43)$ & $<0.001$ \\
\hline Hyponatraemia (<130 mmol/l) & $36(17)$ & $59(15)$ & 0.477 \\
\hline $\begin{array}{l}\text { Hypotension requiring } \\
\text { vasopressors }\end{array}$ & $67(32)$ & $65(16)$ & $<0.001$ \\
\hline Pneumonia & $82(39)$ & $58(15)$ & $<0.001$ \\
\hline Pulmonary oedema & $68(32)$ & $44(11)$ & $<0.001$ \\
\hline Seizure & $25(12)$ & $15(4)$ & $<0.001$ \\
\hline Sepsis & $41(19)$ & $31(8)$ & $<0.001$ \\
\hline Delayed cerebral ischaemia & $73(35)$ & $61(15)$ & $<0.001$ \\
\hline ICU LOS & $13(9-19)$ & $9(7-12)$ & $<0.001$ \\
\hline Hospital LOS & $20(13-31)$ & $13(11-19)$ & $<0.001$ \\
\hline
\end{tabular}

\section{Twelve month outcome}

Twelve month outcome data are presented in figure 1, including 184 patients $(30 \%)$ where $\mathrm{mRS}$ was carried forward. Mortality was higher in patients with early neurological deterioration (18\%, $\mathrm{n}=38$, compared with $1 \%, \mathrm{n}=2$, at 14 days, and $28 \%$, $\mathrm{n}=60$, compared with $3 \%, \mathrm{n}=13$, at 12 months, $\mathrm{p}<0.001$, respectively). Good recovery at 1 year ( $\mathrm{mRS} 0-3$ ) was observed in $52 \%$ of patients with early neurological deterioration $(n=110)$ compared with $88 \%$ without neurological decline in the first $24 \mathrm{~h}$ of admission $(n=351, p<0.001)$. Of the variables associated with mortality and severe disability and mortality in univariate analysis, age, admission Hunt-Hess grade, inhospital hyperglycaemia and early neurological deterioration were independently associated with 12 month outcomes (variables that were forced in the model were gender, admission year and surgical/endovascular treatment) (table 4).

\section{DISCUSSION}

We found that early neurological deterioration after SAH is a strong predictor of death and poor functional recovery at 1 year. Older age and overall clot burden on admission predicted clinical worsening.

The most novel finding in this study is that the initial haemorrhage load is an independent predictor for early neurological deterioration after $\mathrm{SAH}$, regardless of whether the blood is intraventricular, intracerebral or in the subarachnoid space. The association of clot burden and early neurological deterioration may be explained by the evolving mass effect with intracerebral haemorrhage or through the development of obstructive hydrocephalus in patients with intraventricular bleeding. ${ }^{17}$ Although we did not find an association between the Bicaudate Index on admission and neurological deterioration, patients may have developed hydrocephalus thereafter.

One can only speculate why the amount of subarachnoid blood in direct contact with the brain predicts early neurological deterioration. It may be that the toxicity of blood drives early metabolic and electrical failure of brain cells. This concept of neurohaemoinflammation is based on mechanical, biochemical and molecular changes, eventually leading to oedema, neurovascular uncoupling, apopotosis and cell death. ${ }^{18} 19$ Carefully designed studies using multimodal neuromonitoring techniques (microdialysis, brain tissue oxygen and EEG monitoring) or neuroimaging modalities ( $M R$, positron emission tomography, single photon emission computed tomography) may capture these early pathophysiological changes in brain metabolism and physiology.

Given the observed association between clot burden and early worsening, another target for intervention may be found in decreasing haemorrhage related energy demand of the acutely injured brain after poor grade SAH by pharmacological measures or hypothermia. Although intraoperative hypothermia does not improve outcome during aneurysm clipping, ${ }^{20} 21$ early and more prolonged hypothermia may be beneficial as a means of reducing cerebral energy demand or the tissue inflammatory response. Another strategy to minimise the harmful effects of subarachnoid and intraventricular blood might include cisternal or ventricular lavage, kinetic therapy or other methods for promoting early blood clearance. ${ }^{22}$ Early evacuation of packed intraventricular haemorrhage in poor grade SAH patients, however, did not show a favourable outcome. ${ }^{23}$ There is some evidence that lumbar drainage of CSF decreases symptomatic vasospasm and improves outcome after $\mathrm{SAH}^{24}$ 
Figure 1 Outcome of patients with $(A, n=211)$ and without $(B n=398)$ early neurological deterioration using the modified Rankin Scale (mRS) at hospital discharge, and at 3 months and 12 months after subarachnoidal haemorrhage. Percentages of subjects in different $\mathrm{mRS}$ categories are shown group of patients. This figure is only reproduced in colour in the online version. with grades $0-2$ combined as a single
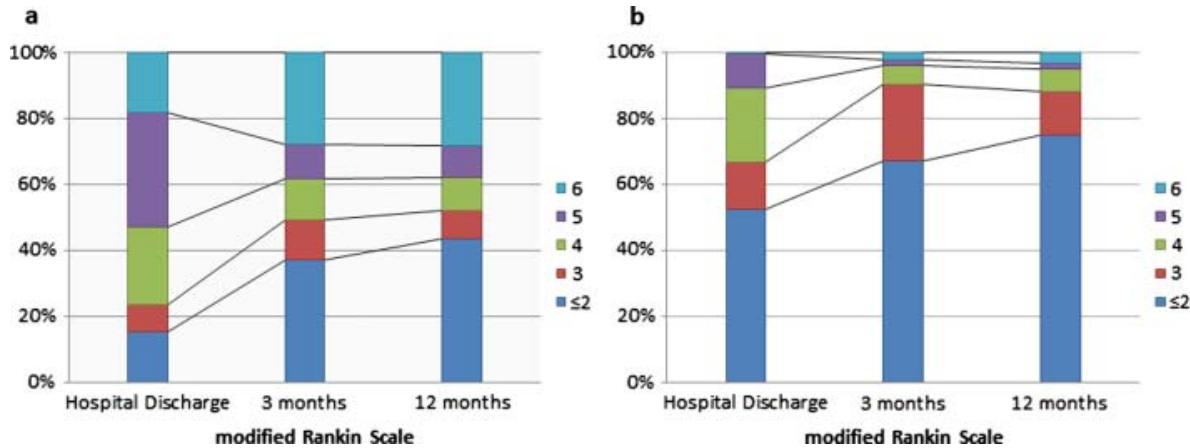

but larger randomised trials are needed to support this intervention.

The prognostic value of early worsening for poor outcome at 12 months is similar to that of previously identified risk factors, such as age, admission Hunt-Hess, rebleeding and aneurysm size. The strong association between worsening and various hospital complications in our study may account in part for the association with poor outcome. Haemorrhage load and the presence of intraventricular blood after SAH have been associated with inhospital complications and increased mortality. 625 The most common hospital complication among patients with early neurological deterioration was fever $(72 \%)$, which is a frequent epiphenomenon in neurocritical care patients, ${ }^{26}$ and is associated with neurological deterioration and poor outcome. ${ }^{2} 72728$ Prevention of fever after $\mathrm{SAH}$ is a widely accepted management strategy and may improve outcome. ${ }^{29}$

Fifty-five per cent of patients with early worsening developed hyperglycaemia during hospitalisation. Prevention of hyperglycaemia has previously been shown to improve outcome in surgical and medical patients, ${ }^{30} 31$ but more recent trials have challenged these findings, ${ }^{32}$ leading to controversy regarding the optimal range of serum glucose in critical care. ${ }^{32}{ }^{33}$ In acutely brain injured patients, the detrimental effect of hyperglycaemia on hospital course and functional outcome has been well studied ${ }^{5} 3435$ but tight glycaemic control (4.4-6.2 mmol/l) has recently been associated with brain metabolic distress, ${ }^{36}$ as brain tissue glucose is primarily regulated by systemic supply. ${ }^{37}$ Prolonged cerebral tissue hypoglycaemia is predictive for poor

Table 4 Predictors of mortality or severe disability and of mortality 12 months after subarachnoidal haemorrhage*

\begin{tabular}{|c|c|c|c|c|c|c|}
\hline \multirow[b]{2}{*}{ Variable } & \multicolumn{3}{|c|}{$\begin{array}{l}\text { Dead or severely } \\
\text { disabledt }\end{array}$} & \multicolumn{3}{|c|}{ Dead } \\
\hline & $\mathbf{O R}$ & $95 \% \mathrm{CI}$ & p Value & $\mathbf{O R}$ & $95 \% \mathrm{CI}$ & p Value \\
\hline Age & 1.05 & $\begin{array}{l}1.03 \text { to } \\
1.07\end{array}$ & $<0.001$ & 1.05 & $\begin{array}{l}1.02 \text { to } \\
1.07\end{array}$ & $<0.001$ \\
\hline Admission Hunt-Hess & 2.6 & $\begin{array}{l}1.9 \text { to } \\
3.4\end{array}$ & $<0.001$ & 2.3 & $\begin{array}{l}1.6 \text { to } \\
3.3\end{array}$ & $<0.001$ \\
\hline $\begin{array}{l}\text { Hyperglycaemia } \\
(>11 \mathrm{mmol} / \mathrm{l}) \ddagger\end{array}$ & 2.2 & $\begin{array}{l}1.2 \text { to } \\
4.1\end{array}$ & $<0.001$ & & & \\
\hline $\begin{array}{l}\text { Neurological } \\
\text { deterioration in first } \\
24 \mathrm{~h}\end{array}$ & 8.4 & $\begin{array}{l}4.9 \text { to } \\
14.5\end{array}$ & 0.01 & 12.1 & $\begin{array}{l}5.7 \text { to } \\
26.1\end{array}$ & $<0.001$ \\
\hline
\end{tabular}

outcome, $^{38} 39$ therefore arguing for a less restrictive target for systemic glycaemic control in acutely brain injured patients. ${ }^{40}$

Several potential weaknesses of this study deserve mention. The single centre design of our study limits the generalisability of our results. The major limitation of this study is that other factors, which potentially cause early neurological deterioration (seizures, stunned myocardium, fever, etc.) were not investigated as these data were not recorded in a time locked way in our database. Furthermore, our data provide no information on early worsening in Hunt-Hess grade V patients, as they were not included in our analysis. Patients may deteriorate prior to hospital admission and after the first $24 \mathrm{~h}$, and our study provides no data on these events. Finally, we analysed only admission predictors of neurological worsening. Due to the complex nature of neurological injury in $\mathrm{SAH}$, we found it impossible to reliably identify specific complications, such as intracranial hypertension, obstructive hydrocephalus, brainstem herniation, seizures, rebleeding or acute cerebral infarctions as the primary cause of early worsening in individual patients. Although we record these complications in our database, we also do not have information regarding the timing of these events. Moreover, the exact hour of SAH bleeding and the exact time of neurological deterioration after admission was not recorded prospectively, which could also have influenced our results. If a 12 month mRS was not performed, the day 14 (or discharge) or 3 month evaluation was carried forward. The model predicting 1 year outcome was recalculated without patients with missing 12 month evaluations (30\%) and did not show a significant change in variables.

\section{CONCLUSIONS}

In conclusion, our findings indicate that early neurological deterioration is an important predictor of poor outcome after $\mathrm{SAH}$. Carefully designed prospective studies are needed to understand the pathophysiology of this phenomenon. Medical therapies aimed at preventing early deterioration after $\mathrm{SAH}$ may improve outcome.

Acknowledgements We thank the Columbia University Neuro-ICU nurses for their overall support of this project.

Contributors RH: idea, writing of the manuscript, analysing and reviewing. PK: analysing and reviewing. MV: reviewing. MJS: analysing and reviewing. LF: reviewing. HL: data editing and reviewing. NDO: reviewing. SEC: reviewing. KL: reviewing. JC: idea and reviewing. SAM: idea and reviewing. NB: idea, reviewing and editing.

Funding This study was supported in part by a Grant-in-Aid (9750432N) from the American Heart Association to SAM.

Competing interests None.

Ethics approval The study was approved by the institutional review board of Columbia University New York.

Provenance and peer review Not commissioned; externally peer reviewed. 
Open Access This is an Open Access article distributed in accordance with the Creative Commons Attribution Non Commercial (CC BY-NC 3.0) license, which permits others to distribute, remix, adapt, build upon this work non-commercially, and license their derivative works on different terms, provided the original work is properly cited and the use is non-commercial. See: http://creativecommons.org/ licenses/by-nc/3.0/

\section{REFERENCES}

1. Bederson JB, Connolly ES Jr, Batjer HH, et al. Guidelines for the management of aneurysmal subarachnoid hemorrhage: a statement for healthcare professionals from a special writing group of the Stroke Council, American Heart Association. Stroke 2009;40:994-1025.

2. Wartenberg KE, Schmidt JM, Claassen J, et al. Impact of medical complications on outcome after subarachnoid hemorrhage. Crit Care Med 2006;34:617-23.

3. Claassen J, Bernardini GL, Kreiter K, et al. Effect of cisternal and ventricular blood on risk of delayed cerebral ischemia after subarachnoid hemorrhage: the Fisher scale revisited. Stroke 2001;32:2012-20.

4. Claassen J, Carhuapoma JR, Kreiter KT, et al. Global cerebral edema after subarachnoid hemorrhage: frequency, predictors, and impact on outcome. Stroke 2002;33:1225-32.

5. Frontera JA, Fernandez A, Claassen J, et al. Hyperglycemia after SAH: predictors, associated complications, and impact on outcome. Stroke 2006;37:199-203.

6. Rosen DS, Macdonald RL, Huo D, et al. Intraventricular hemorrhage from ruptured aneurysm: clinical characteristics, complications, and outcomes in a large, prospective, multicenter study population. J Neurosurg 2007;107:261-5.

7. Fernandez A, Schmidt JM, Claassen J, et al. Fever after subarachnoid hemorrhage: risk factors and impact on outcome. Neurology 2007;68:1013-19.

8. Wijdicks EF, Vermeulen M, Murray GD, et al. The effects of treating hypertension following aneurysmal subarachnoid hemorrhage. Clin Neurol Neurosurg 1990;92:111-17

9. Sundaram MB, Chow F. Seizures associated with spontaneous subarachnoid hemorrhage. Can J Neurol Sci 1986;13:229-31.

10. Vermeulen M, van Gijn J, Hijdra A, et al. Causes of acute deterioration in patients with a ruptured intracranial aneurysm. A prospective study with serial CT scanning. J Neurosurg 1984:60:935-9.

11. Claassen J, Vu A, Kreiter KT, et al. Effect of acute physiologic derangements on outcome after subarachnoid hemorrhage. Crit Care Med 2004;32:832-8.

12. Hunt WE, Hess RM. Surgical risk as related to time of intervention in the repair of intracranial aneurysms. J Neurosurg 1968;28:14-20.

13. Hijdra A, van Giijn J, Nagelkerke NJ, et al. Prediction of delayed cerebral ischemia, rebleeding, and outcome after aneurysmal subarachnoid hemorrhage. Stroke 1988;19:1250-6.

14. Frontera JA, Fernandez A, Schmidt JM, et al. Defining vasospasm after subarachnoid hemorrhage: what is the most clinically relevant definition? Stroke 2009;40:1963-8.

15. Frontera JA, Fernandez A, Schmidt JM, et al. Impact of nosocomial infectious complications after subarachnoid hemorrhage. Neurosurgery 2008;62:80-7.

16. Lyden PD, Lau GT. A critical appraisal of stroke evaluation and rating scales. Stroke 1991;22:1345-52.

17. Vermeij FH, Hasan D, Vermeulen MT, et al. Predictive factors for deterioration from hydrocephalus after subarachnoid hemorrhage. Neurology 1994:44:1851-5.

18. Cahill J, Calvert JW, Zhang JH. Mechanisms of early brain injury after subarachnoid hemorrhage. J Cereb Blood Flow Metab 2006;26:1341-53.

19. Sehba FA, Pluta RM, Zhang JH. Metamorphosis of subarachnoid hemorrhage research: from delayed vasospasm to early brain injury. Mol Neurobiol 2011:43:27-40.
20. Anderson SW, Todd MM, Hindman BJ, et al. Effects of intraoperative hypothermia on neuropsychological outcomes after intracranial aneurysm surgery. Ann Neurol 2006;60:518-27.

21. Todd MM, Hindman BJ, Clarke WR, et al. Mild intraoperative hypothermia during surgery for intracranial aneurysm. N Engl J Med 2005;352:135-45.

22. Hanggi D, Steiger HJ. The influence of cisternal and ventricular lavage on cerebral vasospasm in patients suffering from subarachnoid hemorrhage: analysis of effectiveness. Acta Neurochir Suppl 2011;110:95-8.

23. Shimoda M, Oda S, Shibata M, et al. Results of early surgical evacuation of packed intraventricular hemorrhage from aneurysm rupture in patients with poor-grade subarachnoid hemorrhage. J Neurosurg 1999;91:408-14.

24. Klimo P Jr, Kestle JR, MacDonald JD, et al. Marked reduction of cerebral vasospasm with lumbar drainage of cerebrospinal fluid after subarachnoid hemorrhage. J Neurosurg 2004;100:215-24.

25. Adams HP Jr, Kassell NF, Torner JC. Usefulness of computed tomography in predicting outcome after aneurysmal subarachnoid hemorrhage: a preliminary report of the Cooperative Aneurysm Study. Neurology 1985;35:1263-7.

26. Commichau C, Scarmeas N, Mayer SA. Risk factors for fever in the neurologic intensive care unit. Neurology 2003;60:837-41.

27. Rossi S, Zanier ER, Mauri I, et al. Brain temperature, body core temperature, and intracranial pressure in acute cerebral damage. J Neurol Neurosurg Psychiatry 2001;71:448-54.

28. Ginsberg MD, Busto R. Combating hyperthermia in acute stroke: a significant clinical concern. Stroke 1998;29:529-34.

29. Badjatia N, O'Donnell J, Baker JR, et al. Achieving normothermia in patients with febrile subarachnoid hemorrhage: feasibility and safety of a novel intravascular cooling catheter. Neurocrit Care 2004;1:145-56.

30. Van den Berghe G, Wilmer A, Hermans G, et al. Intensive insulin therapy in the medical ICU. N Engl J Med 2006;354:449-61.

31. van den Berghe G, Wouters P, Weekers F, et al. Intensive insulin therapy in the critically ill patients. N Engl J Med 2001;345:1359-67.

32. Finfer S, Chittock DR, Su SY, et al. Intensive versus conventional glucose control in critically ill patients. N Engl J Med 2009;360:1283-97.

33. Preiser JC, Devos P. Current status of tight blood sugar control. Curr Infect Dis Rep 2008;10:377-82.

34. Badjatia N, Topcuoglu MA, Buonanno FS, et al. Relationship between hyperglycemia and symptomatic vasospasm after subarachnoid hemorrhage. Crit Care Med 2005;33:1603-9.

35. Schlenk F, Vajkoczy P, Sarrafzadeh A. Inpatient hyperglycemia following aneurysmal subarachnoid hemorrhage: relation to cerebral metabolism and outcome. Neurocrit Care 2009:11:56-63.

36. Oddo M, Schmidt JM, Carrera E, et al. Impact of tight glycemic control on cerebral glucose metabolism after severe brain injury: a microdialysis study. Crit Care Med 2008;36:3233-8

37. Seaquist ER, Damberg GS, Tkac I, et al. The effect of insulin on in vivo cerebral glucose concentrations and rates of glucose transport/metabolism in humans. Diabetes 2001:50:2203-9.

38. Vespa PM, McArthur D, O'Phelan K, et al. Persistently low extracellular glucose correlates with poor outcome 6 months after human traumatic brain injury despite a lack of increased lactate: a microdialysis study. J Cereb Blood Flow Metab 2003;23:865-77.

39. Schlenk F, Graetz D, Nagel A , et al Insulin-related decrease in cerebral glucose despite normoglycemia in aneurysmal subarachnoid hemorrhage. Crit Care 2008;12:R9.

40. Oddo M, Schmidt JM, Mayer SA, et al. Glucose control after severe brain injury. Curr Opin Clin Nutr Metab Care 2008:11:134-9. 